ANNALS OF “DUNAREA DE JOS” UNIVERSITY OF GALATI

MATHEMATICS, PHYSICS, THEORETICAL MECHANICS

FASCICLE II, YEAR XI (XLII) 2019, No. 1

Article DOI: https://doi.org/10.35219/ann-ugal-math-phys-mec.2019.1.13

\title{
NATURAL PHENOMENA IMPACTS AND EFFECTS ON TROPOSPHERIC OZONE ASSOCIATED WITH AIR POLLUTION
}

\author{
Radu Costin Pană ${ }^{1}$ \\ ${ }^{1}$ University of Bucharest, Faculty of Physics, Bucharest, Romania, email: rd_pana@yahoo.com
}

\begin{abstract}
This paper presents the impact of lightning on NOx emissions and the further impact on the tropospheric ozone, a strong oxidant, which can harm peoples health. People at greater risk from ozone exposure are, among others, children, older adults and people with certain diseases like asthma or bronchitis. Lightning provides an average $3 \mathrm{ppbv}$ per year of policy relevant background (PRB) ozone concentration and up to $15 \mathrm{ppbv}$ during a single event, meaning that beside igniting forest fires and causing weather-related fatalities among other negative impacts, is also a natural provider of air pollution. With the increase in level of tropospheric ozone driven by the lightning phenomena, the number of people affected by this pollutant located in areas nearby lightning occurrence can increase as well. This means that it is of major importance to find areas where lightning phenomena mostly occur. The investigation has been done using a series of independently provided parameters of lightning flash densities and emissions distributions using data from the Vaisala Network and the Ozone Monitoring Instrument aboard NASA's OTD and LIS satellites.
\end{abstract}

Keywords: air pollution, tropospheric ozone, nitrogen oxides, lightning.

\section{INTRODUCTION}

Atmospheric electric lightning is a high-intensity electric discharge occurring in the atmosphere between electrically charged regions, and can occur either inside a cloud (intranube) or between clouds (internuvens) or between a cloud and the earth (cloud-soil). Lightning is always accompanied by lightning (intense emission of electromagnetic radiation, which has components in the visible range of the spectrum), and thunder (loud sound), in addition to other associated phenomena.

Although intranub and discharges are more frequent, cloud-soil discharges are of greater practical interest to humans. Most of the lightning occur in the tropical zone of the planet and mainly on the emersed lands, associated to convective phenomena of which, when the electric activity is intense, the thunderstorms occur. As high-energy phenomena, lightning usually manifest as an extremely luminous path that travels long distances, sometimes with ramifications. However, there are exotic forms, such as the globular ray, whose nature are unknown, and there are only reports of this phenomena.

The large variation of the electric field of the discharges in the troposphere can give rise to transient luminous events in the high atmosphere. Lightning also originates from other events such as volcanic eruptions, nuclear explosions, and sandstorms. Artificial methods are also used to create 
atmospheric discharges for scientific purposes. Lightning also occurs on other planets in the Solar System, especially on Jupiter and Saturn.

From the formation of the Earth, the high temperatures of the crust were responsible for great and permanent storms that remained furious, giving rise to the oceans. Water, as it performed its cycle, carried with it chemical elements, such as carbon and nitrogen, which been accumulated in primitive seas. Ultraviolet rays were essential in combination with inorganic compounds and their transformation into amino acids, essential components for the emergence of life as we know it [1].

Electric discharges are the main source of nitrites and nitrates, essential for plant life. Plants are not able to directly use atmospheric nitrogen. The lightning is responsible for such chemical reactions, thus maintaining the nitrogen cycle [1].

The lightning, which is most often associated with storms, is a gigantic spark of static electricity, through which a conductive channel is formed and electric charges are transferred. The most common type of lightning occurs within the clouds themselves, although there are discharges between two clouds, between the cloud and the air, and between the cloud and the ground. It all depends on how the electric charges are distributed within the clouds [2].

In general, load distributions in convective clouds generate an intense electric field. At the top of the cloud, which consists of a cumulus-nimbus type that is flattened and extends horizontally, positive charges build up on the small ice crystals from the convection currents. In the center, usually in a range where the temperature is between -20 and $-10^{\circ} \mathrm{C}$, the negative charges are in excess.

The dipoles formed have each, dozens of coulombs, separated by a few kilometers vertically. At the base of the cloud is typically formed a small region of positive charges, whose charge does not exceed a few coulombs. In more developed storms, the electrical distribution is much more complex [3].

Lightning generates relatively large but uncertain quantities of nitrogen oxides (NOx), critical precursors for ozone and hydroxyl radical $(\mathrm{OH})$, the primary tropospheric oxidants. Lightning NOx strongly influences background ozone and $\mathrm{OH}$ due to high ozone production efficiencies in the free troposphere, effecting small but non-negligible contributions to surface pollutant concentrations.

Lightning globally contributes 3-4 parts per billion by volume (ppbv) of simulated annualmean policy-relevant background surface ozone, comprised of local, regional and hemispheric components, and up to $18 \mathrm{ppbv}$ during individual events [4].

\section{LIGHTNING IMPACT ON AIR POLLUTION}

Lightning impacts through extreme temperatures of lightning channels impacts the quantities of trace gases in the troposphere region by producing nitrogen oxides $\left(\mathrm{NO}_{\mathrm{X}}=\mathrm{NO}+\mathrm{NO}_{2}\right)$, which are reactive and combined with water vapors, sunlight presence and organic compounds that are volatile creates and generates hydroxyl radicals $(\mathrm{OH})$ and of course tropospheric ozone $\left(\mathrm{O}_{3}\right)$ which is an air pollutant, creating many problems that causes harm [5].

Furthermore, despite pollutants reduction efforts or even lack of anthropogenic created ozone it is noticeable how pollution levels caused by ozone are still at a very high level in areas where lightning mostly occurs [6].

Because the lightning channel temperature that increases significantly in a short period of time and afterwards a steep decrease during the same area facilitates conversions of $\mathrm{N}_{2}$ and $\mathrm{O}_{2}$, otherwise stable, into $\mathrm{NO}_{2}, \mathrm{CO}$, and ozone gases [7].

High levels of $\mathrm{NO}_{\mathrm{X}}$ trace gases which can generate $\mathrm{O}_{3}$ can be observed immediately after thunderstorm activities with the help of NASA OTD and LIS satellites as shown in Figure 2.

\section{RESULTS}

We present in the following the global lightning flash distribution during the period of time 2012-2016 as shown in Figure 1. with the help of Vaisala satellites network. As well we present further 
the global tropospheric ozone distribution as shown immediately after thunderstorm activities with the help of NASA OTD and LIS satellites data in Fig. 2, 3, 4, 5.

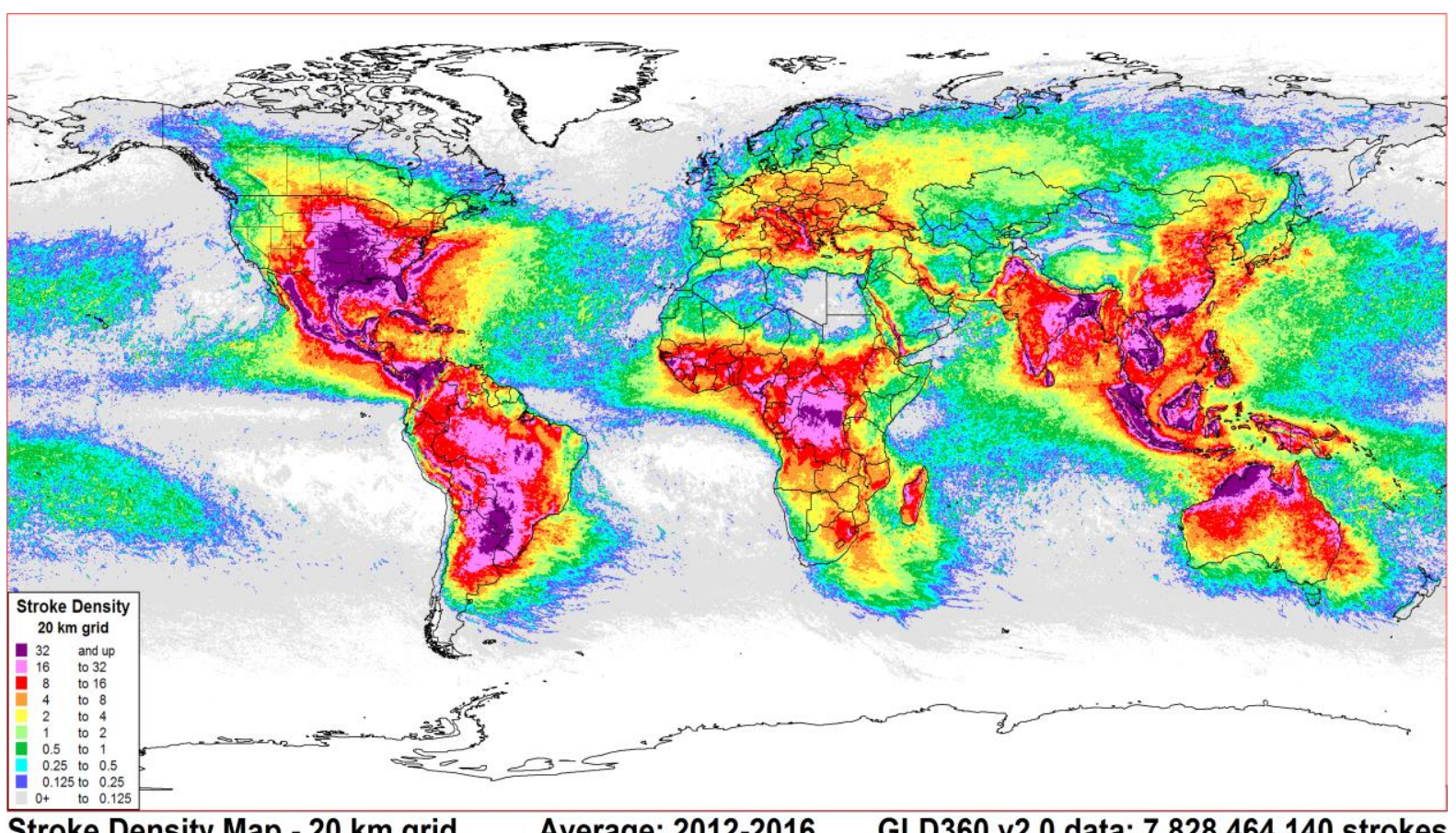

Stroke Density Map - 20 km grid Average: 2012-2016 GLD360 v2.0 data: 7,828,464,140 strokes Fig. 1 The global lightning flash distribution courtesy of VAISALA satellites network

\section{$\mathrm{O}_{3}$}

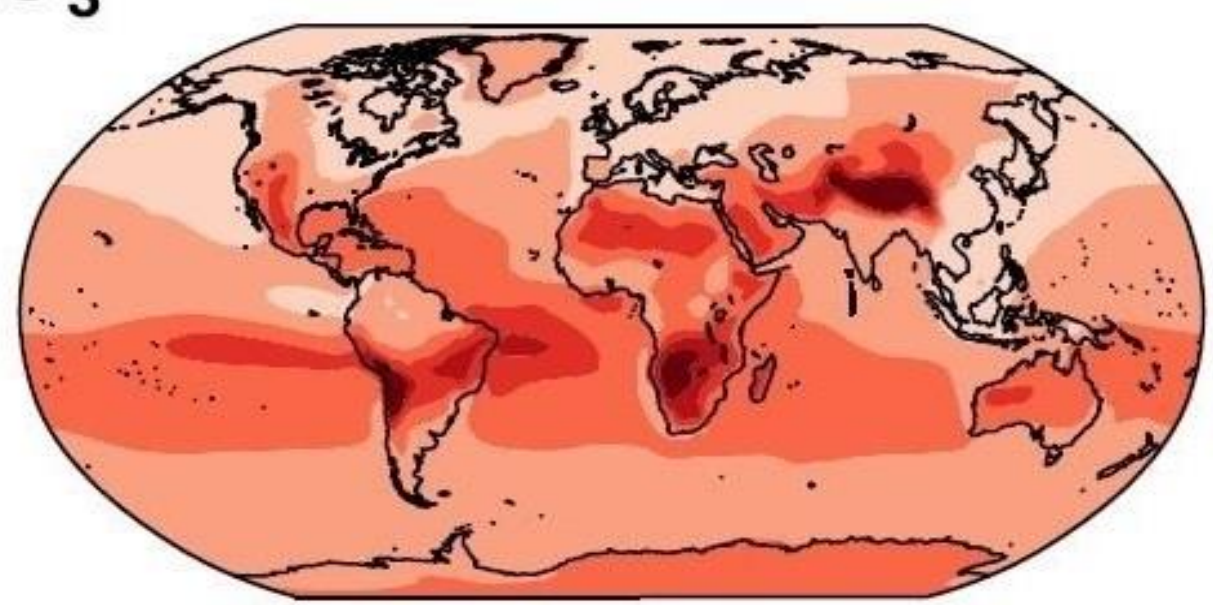

ppbv

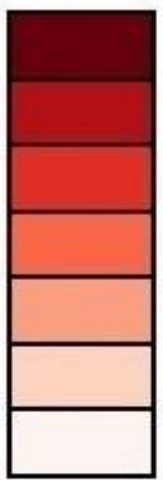

5

3

Fig. 2 Average global troposheric ozone distribution immediately after thunderstorm activities 
$\mathrm{O}_{3}$

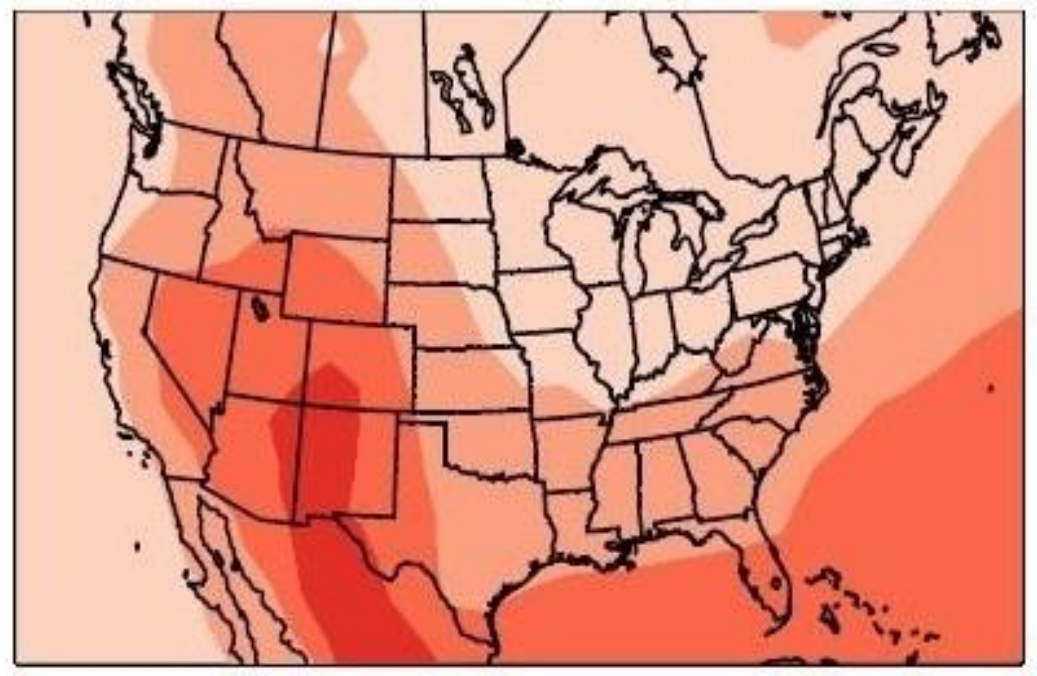

ppbv

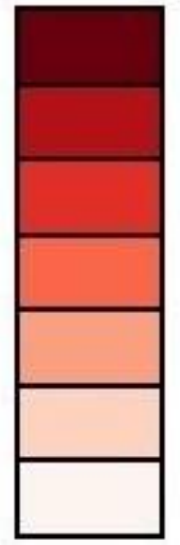

5

3

1

Fig. 3 Average troposheric ozone distribution over United States of America immediately after thunderstorm activities

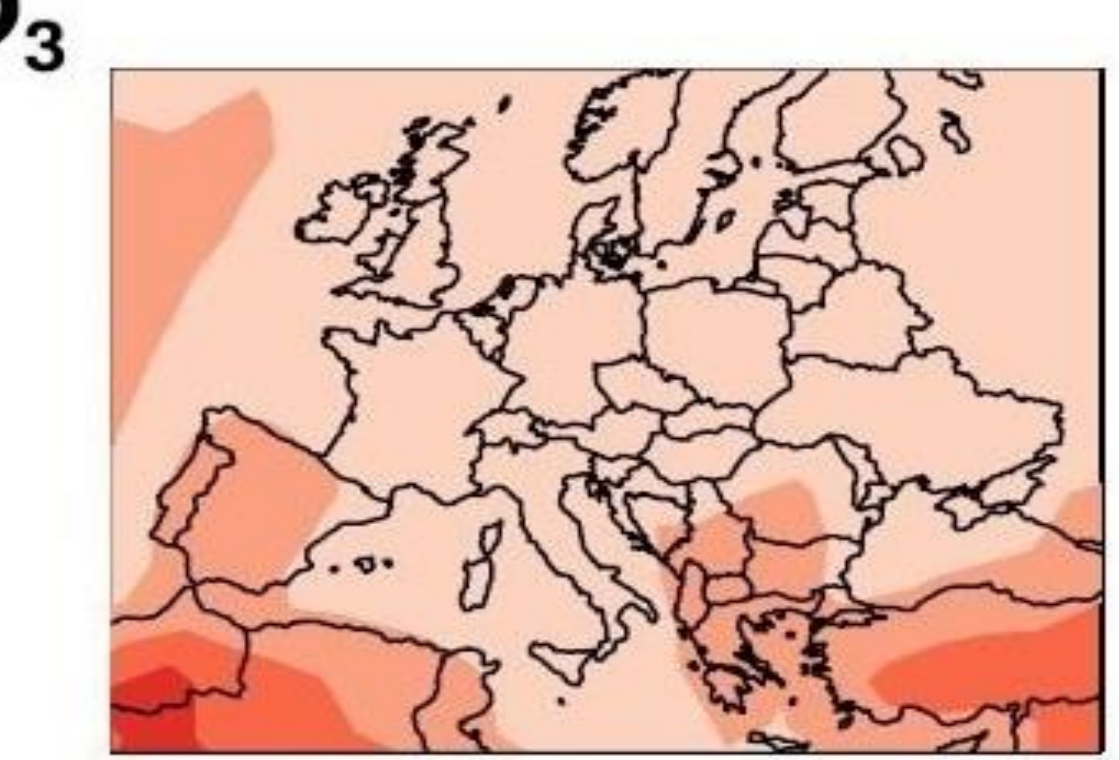

ppbv

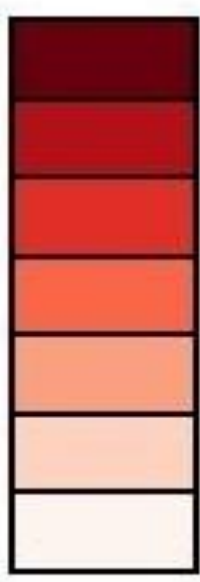

5

3

Fig. 4 Average troposheric ozone distribution over Europe immediately after thunderstorm activities 


\section{$\mathrm{O}_{3}$}

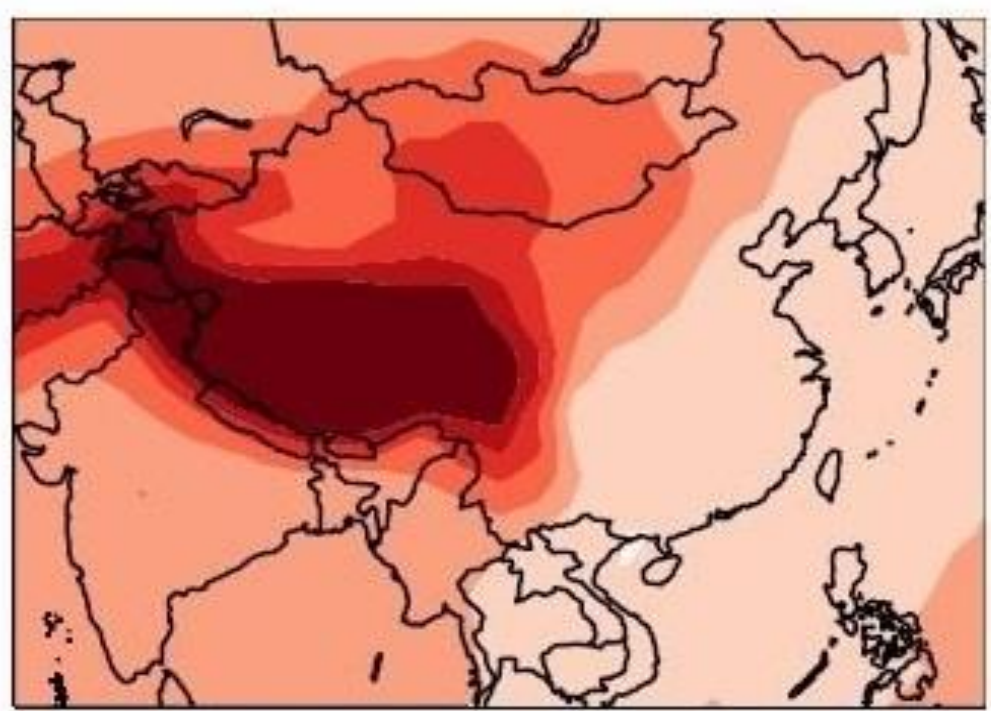

\section{ppbv}

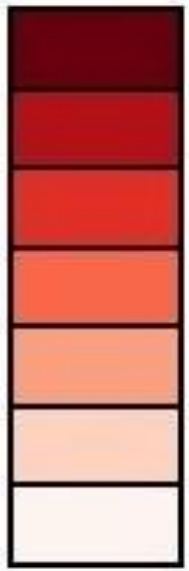

5

3

Fig. 5 Average troposheric ozone distribution over Southeastern Asia immediately after thunderstorm activities

\section{CONCLUSIONS}

Lightning generates relatively large but uncertain quantities of $\mathrm{NO}_{\mathrm{x}}$, a critical precursor for the production of ozone and hydroxyl radical $(\mathrm{OH})$ in the troposphere. Lightning $\mathrm{NO}_{\mathrm{x}}$ has a disproportionately stronger influence on ozone and $(\mathrm{OH})$ than surface- $\mathrm{NO}_{\mathrm{x}}$ sources above the boundary layer where most lightning $\mathrm{NO}_{\mathrm{x}}$ is released. Direct exposure to lightning $\mathrm{NO}_{\mathrm{x}}$ at the surface is small and short-lived relative to exposure guidelines. Few ground-based observation studies have estimated impacts of fresh lightning $\mathrm{NO}_{x}$ at the surface.

\section{References}

1. Mangold V. L., Life and Lightning: The Good Things of Lightning, Universal Publishers, Orlando, pp. 33-40, 1999.

2. Bouquegneau C., Rakov V., How dangerous is lightning, Dover Publications, New York, pp. 31-58, 2010.

3. Lamb D., Verlinde J., Physics and Chemistry of Clouds, Cambridge University Press, Cambridge, pp. 242-318, 2011.

4. Prather M. J., Holmes C. D., Hsu J., Reactive greenhouse gas scenarios: Systematic exploration of uncertainties and the role of atmospheric chemistry, Geophys. Res. Lett., 39(9), L9803, 2012.

5. Alexander B., Mickley L. J., Paleo-Perspectives on Potential Future Changes in the Oxidative Capacity of the Atmosphere Due to Climate Change and Anthropogenic Emissions, Current Pollution Reports, 1(2), pp. 57-69, 2015.

6. Lamarque J. F., Shindell D. T., Josse B., Young P. J., Cionni I., Eyring V., Bergmann D., Cameron-Smith P. J., Collins W. J., Doherty R., Dalsøren S., Faluvegi G., Folberth G., Ghan S. J., Horowitz L. W., Lee Y. H., MacKenzie I. A., Nagashima T., Naik V., Plummer D., Righi M., Rumbold S. T., Schulz M., Skeie R. B., Stevenson D. S., Strode S., Sudo K., Szopa S., Voulgarakis A., Zeng G., The Atmospheric Chemistry and Climate Model Intercomparison Project (ACCMIP): overview and description of models, simulations and climate diagnostics, Geosci. Model. Dev., 6(1), pp. 179-206, 2013. 
7. Huntrieser H., Hoeller H., Grewe V., Thunder storms: Trace Species Generators, Atmospheric Physics, Springer Berlin Heidelberg, Berlin, pp. 115-133, 2012. 